\title{
Global quieting of high-frequency seismic noise due to COVID-19 pandemic lockdown measures
}

Thomas Lecocq ${ }^{1 *}$, Stephen P. Hicks ${ }^{2}$, Koen Van Noten', Kasper van Wijk ${ }^{3}$, Paula Koelemeijer ${ }^{4}$, Raphael S. M. De Plaen $^{5}$, Frédérick Massin ${ }^{6}$, Gregor Hillers ${ }^{7}$, Robert E. Anthony ${ }^{8}$, Maria-Theresia Apoloner ${ }^{9}$, Mario ArroyoSolórzano $^{10}$, Jelle D. Assink ${ }^{11}$, Pinar Büyükakpınar ${ }^{12,13}$, Andrea Cannata ${ }^{14,15}$, Flavio Cannavo ${ }^{15}$, Sebastian Carrasco $^{16}$, Corentin Caudron ${ }^{17}$, Esteban J. Chaves ${ }^{18}$, David G. Cornwell ${ }^{19}$, David Craig ${ }^{20}$, Olivier F. C. den Ouden $^{11,21}$, Jordi Diaz ${ }^{22}$, Stefanie Donner ${ }^{23}$, Christos P. Evangelidis ${ }^{24}$, Läslo Evers ${ }^{11,21}$, Benoit Fauville ${ }^{25}$, Gonzalo A. Fernandez ${ }^{26}$, Dimitrios Giannopoulos ${ }^{27,28}$, Steven J. Gibbons ${ }^{29}$, Társilo Girona ${ }^{30}$, Bogdan Grecu ${ }^{31}$, Marc Grunberg $^{32}$, György Hetényi ${ }^{33}$, Anna Horleston ${ }^{34}$, Adolfo Inza ${ }^{35}$, Jessica C. E. Irving ${ }^{34,36}$, Mohammadreza Jamalreyhani $^{37,13}$, Alan Kafka ${ }^{38}$, Mathijs R. Koymans ${ }^{11,21}$, Celeste R. Labedz ${ }^{39}$, Eric Larose ${ }^{17}$, Nathaniel J. Lindsey $^{40}$, Mika McKinnon ${ }^{41,42}$, Tobias Megies ${ }^{43}$, Meghan S. Miller ${ }^{44}$, William Minarik ${ }^{45,46}$, Louis Moresi ${ }^{44}$, Víctor H. Márquez-Ramírez ${ }^{5}$, Martin Möllhoff ${ }^{20}$, Ian M. Nesbitt ${ }^{4748}$, Shankho Niyogi ${ }^{49}$, Javier Ojeda ${ }^{50}$, Adrien Oth $^{51}$, Simon Proud ${ }^{52}$, Jay Pulli ${ }^{53,38}$, Lise Retailleau ${ }^{54,55}$, Annukka E. Rintamäki ${ }^{7}$, Claudio Satriano ${ }^{54}$, Martha K. Savage $^{56}$, Shahar Shani-Kadmiel ${ }^{21}$, Reinoud Sleeman ${ }^{11}$, Efthimios Sokos ${ }^{57}$, Klaus Stammler ${ }^{23}$, Alexander E. Stott $^{58}$, Shiba Subedi ${ }^{33}$, Mathilde B. Sørensen ${ }^{59}$, Taka'aki Taira ${ }^{60}$, Mar Tapia $^{61}$, Fatih Turhan ${ }^{12}$, Ben van der Pluijm $^{62}$, Mark Vanstone ${ }^{63}$, Jerome Vergne ${ }^{64}$, Tommi A. T. Vuorinen ${ }^{7}$, Tristram Warren ${ }^{65}$, Joachim Wassermann $^{43}$, Han Xiao ${ }^{66}$

${ }^{1}$ Seismology-Gravimetry, Royal Observatory of Belgium, Avenue circulaire 3, 1180 Brussels, Belgium. ${ }^{2}$ Department of Earth Science and Engineering, Imperial College London, London, UK. ${ }^{3}$ Department of Physics, University of Auckland, New Zealand. ${ }^{4}$ Department of Earth Sciences, Royal Holloway University of London, Egham, UK. ${ }^{5}$ Centro de Geociencias, Universidad Nacional Autónoma de México, Campus Juriquilla, Querétaro, Mexico. ${ }^{6}$ Swiss Seismological Service, ETH Zurich, Sonneggstrasse 5 , CH-8092, Zurich, Switzerland. 'Institute of Seismology, University of Helsinki, Helsinki, Finland. ${ }^{8}$ U.S. Geological Survey - Albuquerque Seismological Laboratory, New Mexico, USA. ${ }^{~ Z}$ Zentralanstalt für Meteorologie und Geodynamik (ZAMG), Vienna, Austria. ${ }^{10}$ Escuela Centroamericana de Geología, Universidad de Costa Rica, San José, Costa Rica. ${ }^{11}$ R\&D Seismology and Acoustics, Royal Netherlands Meteorological Institute (KNMI), Utrechtseweg 297, 3731 GA De Bilt, Netherlands. ${ }^{12 K a n d i l l i}$ Observatory and Earthquake Research Institute, Boğaziçi University, Istanbul, Turkey. ${ }^{13}$ GFZ German Research Centre for Geosciences, Potsdam, Germany. ${ }^{14}$ Dipartimento di Scienze Biologiche, Geologiche e Ambientali, Università Degli Studi di Catania, Catania, Italy. ${ }^{15}$ Istituto Nazionale di Geofisica e Vulcanologia, Osservatorio Etneo, Catania, Italy. ${ }^{16}$ Bensberg Observatory, University of Cologne, Cologne, Germany. ${ }^{17}$ Univ. Grenoble Alpes, Univ. Savoie Mont Blanc, CNRS, IRD, IFSTTAR, ISTerre, 38000 Grenoble, France. ${ }^{18}$ Volcanological and Seismological Observatory of Costa Rica at Universidad Nacional (OVSICORI-UNA), Costa Rica. ${ }^{19 D e p a r t m e n t ~ o f ~ G e o l o g y ~ \& ~ G e o p h y s i c s, ~ S c h o o l ~ o f ~}$ Geosciences, University of Aberdeen, King's College, Aberdeen, AB24 3UE, UK. ${ }^{20}$ Dublin Institute for Advanced Studies, Geophysics Section, 5 Merrion Square, D02 Y006 Dublin, Ireland. ${ }^{21}$ Dept. of Geoscience and Engineering, Delft University of Technology, Stevinweg 1, 2628 CN Delft, Netherlands. ${ }^{22}$ Geosciences Barcelona, CSIC, Barcelona, Spain. ${ }^{23}$ Federal Institute for Geosciences and Natural Resources (BGR), Hannover, Germany. ${ }^{24}$ Institute of Geodynamics, National Observatory of Athens, Greece. ${ }^{25}$ Noise Department, Brussels Environment, Brussels-Capital Region, Belgium. ${ }^{26}$ Observatorio San Calixto, Bolivia. ${ }^{27}$ Seismotech S.A., Athens, Greece. ${ }^{28} \mathrm{Hellenic}$ Mediterranean University, Dept. of Environmental \& Natural Resources Engineering, Laboratory of Geophysics \& Seismology, Chania, Greece. ${ }^{29}$ Norges Geotekniske Institutt, Sognsveien 72, 0855 Oslo, Norway. ${ }^{30}$ Geophysical Institute, University of Alaska Fairbanks, Alaska 99775, USA. ${ }^{31}$ National Institute for Earth Physics, Calugareni 12, Magurele, Romania. ${ }^{32}$ Réseau National de Surveillance Sismique (RENASS); Université de Strasbourg, CNRS, EOST UMS830, 5 rue René Descartes, F-67084 Strasbourg Cedex, France. ${ }^{33}$ Institute of Earth Sciences, Faculty of Geosciences and Environment, University of Lausanne, Lausanne, Switzerland. ${ }^{4}$ School of Earth Sciences, University of Bristol, Queen's Road, Bristol, BS8 1RJ, UK. ${ }^{35}$ Instituto Geofisico del Peru, Lima, Peru. ${ }^{36}$ Department of Geosciences, Princeton University, NJ, USA. ${ }^{37}$ Institute of Geophysics, University of Tehran, Iran. ${ }^{38}$ Weston Observatory, Department of Earth and Environmental Sciences, Boston College, Weston, MA, USA. ${ }^{39}$ Seismological Laboratory, California Institute of Technology, Pasadena, CA, USA. ${ }^{40}$ Geophysics Department, Stanford University, Stanford, CA, USA. ${ }^{41}$ SETI Institute, Mountain View, CA, USA. ${ }^{42}$ Faculty of Science, Department of Earth, Ocean and Atmospheric Sciences, University of British Columbia, Canada. ${ }^{43}$ Ludwig-Maximilians-Universität München, Munich, Germany. ${ }^{44}$ Research School of Earth Sciences, Australian National University, Canberra, ACT Australia. ${ }^{45}$ Department of Earth and Planetary Sciences, McGill University, Montréal, QC, Canada. ${ }^{46}$ GEOTOP Research Centre, Montréal, QC, Canada. ${ }^{47}$ Raspberry Shake, S.A. ${ }^{48}$ Department of Earth and Climate Science, University of Maine, Orono, ME, USA. ${ }^{49}$ University of California, Riverside, USA. ${ }^{50}$ Departamento de Geofísica, Universidad de Chile, Santiago, Chile. ${ }^{51}$ European Center for Geodynamics and Seismology; 19, rue Josy Welter; L-7256 Walferdange, Grand Duchy of Luxembourg. ${ }^{52}$ National Centre for Earth Observation, Department of Physics, University of Oxford, UK. ${ }^{53}$ Raytheon BBN Technologies, Arlington, VA, USA. ${ }^{54}$ Université de Paris, Institut de physique du globe de Paris, CNRS, F-75005 Paris, France. ${ }^{55}$ Observatoire Volcanologique du Piton de la Fournaise, Institut de physique du globe de Paris, F-97418 La Plaine des Cafres, France. ${ }^{56}$ School of Geography, Environment and Earth Sciences, Victoria University of Wellington, New Zealand. ${ }^{77}$ Department of Geology, University of Patras, Patras, 26504 Rio, Greece. ${ }^{58}$ Department of Electrical and Electronic Engineering, Imperial College London, South Kensington Campus, London, SW7 2AZ, UK. ${ }^{59}$ Department of Earth Science, University of Bergen, Bergen, Norway ${ }^{60}$ Berkeley Seismological Laboratory, University of California Berkeley, Berkeley, USA. ${ }^{61}$ Laboratori d'Estudis Geofísics Eduard Fontserè, Institut d'Estudis Catalans (LEGEF-IEC), Barcelona, Spain. ${ }^{62}$ Department of Earth and Environmental Sciences, University of Michigan-Ann Arbor, MI, USA. ${ }^{63}$ Geology Department, Truro School, Trennick Lane, Truro, Cornwall, TR1 1TH, UK. ${ }^{64}$ Institut de Physique du Globe de Strasbourg ; UMR 7516, Université de Strasbourg/EOST, CNRS ; 5 rue René Descartes, F-67084 Strasbourg Cedex, France. ${ }^{65}$ Department of Physics, University of Oxford, UK. ${ }^{66}$ Department of Earth Science and Earth Research Institute, University of California, Santa Barbara, CA, USA.

*Corresponding author. Email: thomas.lecocq@seismology.be 
Human activity causes vibrations that propagate into the ground as high-frequency seismic waves. Measures to mitigate the COVID-19 pandemic caused widespread changes in human activity, leading to a months-long reduction in seismic noise of up to $50 \%$. The 2020 seismic noise quiet period is the longest and most prominent global anthropogenic seismic noise reduction on record. While the reduction is strongest at surface seismometers in populated areas, this seismic quiescence extends for many kilometers radially and hundreds of meters in depth. This provides an opportunity to detect subtle signals from subsurface seismic sources that would have been concealed in noisier times and to benchmark sources of anthropogenic noise. A strong correlation between seismic noise and independent measurements of human mobility suggests that seismology provides an absolute, real-time estimate of population dynamics.

Seismometers record signals from more than just earthquakes; interactions between the solid Earth and fluid bodies, such as ocean swell and atmospheric pressure $(1,2)$, are now commonly used to image and monitor the subsurface (3). Human activity is a third source of seismic signal. Nuclear explosions and fluid injection/extraction result in impulsive signals, but everyday human activity is recorded as a near-continuous signal especially on seismometers in urban environments. These complicated signals are the superposition of a wide variety of activities happening at different times and places at or near the Earth's surface, but are typically stronger during the day than at night, weaker on weekends than weekdays, and stronger near population centers (4-7). Seismometers in urban environments are important to maximize the spatial coverage of seismic networks and to warn of local geologic hazards (8), even though anthropogenic seismic noise degrades their capability to detect transient signals associated with earthquakes and volcanic eruptions. Understanding urban seismic sources is therefore vital. However, research studies have been limited to confined areas or distinct events, such as road traffic $(9$, $10)$, public transport $(7,11)$, and "football quakes" $(11,12)$. Broad analysis of the long-term global anthropogenic seismic wavefield has been lacking. The impact of large, coherent changes in human behavior on seismic noise is unknown, as is how far it propagates and whether seismic recordings offer a coarse proxy for monitoring human activity patterns. Answering these questions has proven challenging: datasets are large, monitoring network heterogeneous, and the many possible noise sources likely vary spatially and overlap in time (13).

The COVID-19 outbreak was declared a global health emergency in January 2020 (14) and a pandemic in March by the World Health Organization. The outbreak resulted in emergency measures to reduce the basic reproduction rate of the virus $(R O)(15)$, beginning in China, Italy, and then followed by most countries. These measures disrupted social and economic behavior (16), industry (17), and tourism (18). In this paper, we use "lockdown" to broadly encompass many types of emergency measures, such as full quarantine (e.g., Wuhan, China (19-21)), enforced physical distancing (e.g., Italy; UK), travel restrictions (22), widespread closure of services and industry, or any other emergency measures. These drastic changes to daily life provide a unique opportunity to study their environmental impacts, such as reductions in nitrous oxide emissions in the atmosphere (23). Recordings of human-generated seismic vibrations that travel through the solid Earth provide insights into the dynamics of pandemic lockdowns.

We assessed the effects of COVID-19 lockdowns on highFrequency (4-14 Hz) Seismic Ambient Noise (hiFSAN; (24)). We compiled a global seismic noise dataset using verticalcomponent seismic waveform data from 337 broadband and individually operated citizen seismometer stations (24), such as Raspberry Shakes (RS), with a self-noise well below the ground motion generated by anthropogenic noise (25), and flat responses in the target frequency band (Fig. 1). For 268 seismic stations, we obtained usable data (e.g., no large data gaps, working sensors) and found significant reductions in hiFSAN during local lockdown measures at 185 stations (Fig. 2). Periods that are often seismically quiet include weekends, and the Christmas / New Year holidays for those locations where these are celebrated. We found a near-global reduction in noise, commencing in China in late Jan 2020, then followed by Europe and the rest of the world in Mar to Apr 2020. The noise level we observe during lockdowns lasted longer and was often quieter than the Christmas to New Year period.

In China (Fig. 3A), the COVID-19 outbreak and subsequent emergency measures occurred during Chinese New Year (CNY). In Enshi city, Hubei province, where the outbreak began (26), hiFSAN in 2020 clearly diverges from the normal annual reduction during CNY. The hiFSAN level remained at a minimum for several weeks after CNY. This minimum was demarcated by the start and end of quarantine in Hubei. While such strict quarantine measures were not enforced in Beijing, local hiFSAN reductions are stronger and longer than recent years. As of the end date of our analysis, Beijing has still not reached the average hiFSAN level of 
previous years, suggesting the impact of COVID-19 is still restricting anthropogenic noise there. We noticed a later hiFSAN lockdown reduction in Apr 2020 in Heilongjiang, in NE China, near the Russian border.

While we see seismic effects of lockdown in areas with low population density estimates ( $<1$ person per $\mathrm{km}^{2}$, Fig. 1), the strongest hiFSAN reduction occurs in populated environments. For a permanent seismic station in Sri Lanka, a 50\% reduction in hiFSAN occurred after lockdown, the strongest we observed in the available data from that station since at least July 2013 (fig. S2). In Central Park, New York, on Sunday nights, hiFSAN was $10 \%$ lower during the lockdown compared to before it (fig. S3).

Seismic networks in populated areas allow us to correlate hiFSAN with other human activity measurements, such as audible recordings and flight data (24). At a surface station in Brussels, Belgium (Fig. 3B), we found a $33 \%$ reduction in hiFSAN after lockdown. We compared this with data from a nearby microphone, located close to a major road, that mainly records audible traffic noise. We found a high correlation between pre-lockdown hiFSAN and audible noise, both showing characteristic diurnal and weekly changes. However, during lockdown, audible noise reductions are more pronounced, suggesting that seismometers are sensitive to a wider distribution of seismic sources, not solely to the nearby traffic. Audible and hiFSAN levels then gradually increase after Apr 2020. Independent mobility data (24) provide insights into what cause these changes. Mobility correlates with hiFSAN at lockdown, with correlation coefficients exceeding 0.8 (24), except for time spent at places of residence (Google's "residential" category), which is expected given the increased number of people spending more time at home due to government restrictions.

Citizen seismometers provide a different urban ground motion dataset, with denser coverage in some places. Large hiFSAN drops especially occurred at schools and universities following lockdown-related closures (e.g., in Boston and Michigan (US) and Cornwall (UK)), fig. S4). The hiFSAN level is even $20 \%$ lower than during school holidays, indicating sensitivity to the environment outside of the school.

The pandemic impacted tourism, for example, during the holiday season in the Caribbean. In Barbados (Fig. 3C), hiFSAN decreased by $\sim 45 \%$ following lockdown on 28 March 2020, through April 2020 and stayed $\sim 50 \%$ below levels observed in previous years for the same period. However, seismic noise levels started to decrease 1-2 weeks before a local curfew started. Local flight data (24) imply travel to Barbados started decreasing after 21 March 2020 and the overall reduction in hiFSAN might be due in part to tourists repatriating. We also observed noise reductions due to reduced tourist activity at ski resorts in Europe (Zugspitze) and the US (Mammoth Mountain) (fig. S5).
While we saw lockdown effects most strongly at surface stations, we also detected them underground. Seismometers installed in boreholes to minimize the effects of anthropogenic noise on the data monitor potential hazards associated with the Auckland Volcanic Field, New Zealand $(6,8,27)$. Station HBAZ is $380 \mathrm{~m}$ below the city, while MBAZ is at $98 \mathrm{~m}$ depth, $14 \mathrm{~km}$ from the city center on the uninhabited Motutapu island (Fig. 3D). The hiFSAN level at both stations varies between weekdays and weekends before the lockdown, suggesting that both are sensitive to anthropogenic activity. While the island station is quieter overall, the lockdown instigated a reduction in hiFSAN by a factor of 2 for both stations. We attribute the remaining hiFSAN maxima on the island (mid Apr 2020; early May 2020) to strong winds and high waves. On 27 April 2020, New Zealand lifted restrictions, with hiFSAN increasing to the pre-lockdown levels.

The reduction of hiFSAN is weaker in less populated areas, such as at Rundu which is located along the NamibiaAngola border (Fig. 3E). After COVID-19 was confirmed in Namibia, an emergency was declared on 17 Mar 2020 to restrict mobility, followed by full lockdown on 27 Mar 2020. These measures are reflected in $>25 \%$ hiFSAN reduction compared to pre-lockdown. Despite Rundu having a population roughly 8 and 5 times less dense than Brussels and Auckland, respectively (28), we observed a similarly high correlation between seismic and mobility data. The Black Forest Observatory in Germany is an even more remote station, located 150$170 \mathrm{~m}$ below the surface in crystalline bedrock. Considered a reference low-noise laboratory (29), even there we found a small hiFSAN reduction during lockdown nights (fig. S6), corresponding to the lowest hiFSAN since at least 25 Dec 2015.

We have provided a global-scale analysis of high-frequency anthropogenic seismic noise. Global median hiFSAN dropped by as much as 50\% during March to May 2020 (Fig. 4). The length and quiescence of this period represents the longest and most coherent global seismic noise reduction in recorded history, highlighting how human activities impact the solid Earth. A globally high correlation exists between changes in hiFSAN and population mobility (24), with correlations exceeding 0.9 for many categories.

This distinct low-noise period will help to optimize seismic monitoring (4). Analyzing the full spectrum of seismogenic behavior, including the smallest earthquakes, is essential for monitoring fault dynamics over seismic cycles, and for earthquake forecasting and seismic hazard assessment. Small earthquakes should dominate datasets (30), but typical operational catalogs using amplitude-based detection lack many of the smallest earthquakes (31). This detection issue is especially problematic in populated areas, where anthropogenic noise energy interferes with earthquake signals. This problem is exemplified by recordings of a M5.0 earthquake at $15 \mathrm{~km}$ depth $\mathrm{SW}$ of Petatlan, Mexico during 
lockdown (fig. S7). An earthquake with this magnitude and source mechanism occurring during the daytime could typically only be observed at stations in urban environments by filtering the signal. However, the reduction of seismic noise by $\sim 40 \%$ during lockdown made this event visible without any filtering required at a RS station in Querétaro city, 380 $\mathrm{km}$ away. Low noise levels during COVID-19 lockdowns could thus allow detection of signals from new sources in areas with incomplete seismic catalogs. Such newly identified signals could be used as distinct templates (30) for finding similar waveforms in noisier data pre- and post-lockdown. This approach also works for tremor signals masked by anthropogenic noise, yet vital for monitoring potential volcanic unrest (6). Although broadband sensors in rural environments are impacted less by anthropogenic noise, any densification of and reliance on low-cost sensors in urban areas, such as RS and low-cost accelerometers (32), will require a better understanding of anthropogenic noise sources to suppress false detections. As populations increase globally, more people become exposed to potential natural and induced geohazards (33). Urbanization will increase anthropogenic noise in exposed areas, further complicating seismic monitoring. Characterizing and minimizing anthropogenic noise is increasingly important for accurately detecting and imaging the seismic signatures of potentially harmful subsurface hazards.

Anthropogenic seismic noise is thought to be dominated by noise sources less than $1 \mathrm{~km}$ away $(5-7,11,34)$. Because population mobility generates time-varying loads that radiate energy through the shallow subsurface as Rayleigh waves (11), local effects, such as construction sites, and heavy machinery, can impact individual stations. However, the unique 2020 seismic noise quiet period reveals that when considering multiple stations or whole networks over longer timescales, the anthropogenic seismic wavefield affects large areas. With denser networks and more citizen sensors in urban environments, more features of the seismic noise, rather than just amplitude, will become usable and will help to identify different anthropogenic noise sources $(10,35)$. Characterizing these sources will be useful for imaging the shallow subsurface in 3D in urban areas using high-frequency anthropogenic ambient noise $(36,37)$. Our finding of a distributed noise field is supported by the strong correlations with independent mobility data (Fig. 4). In contrast to mobility data, publicly available data from existing seismometer networks provide an objective absolute baseline of human activity levels. Therefore, hiFSAN can serve as a near-real-time technique for monitoring anthropogenic activity patterns with fewer potential privacy concerns than mobility data. In addition, industrial activities may not be captured in mobility data, but leave a seismic noise signature. The 2020 seismic quiet period is a baseline for using seismic properties (34) to identify and isolate the sources contributing to the anthropogenic noise wavefield, especially when combined with data indicative of human behavior. The seismic observations of human activity during the COVID-19 lockdown allow us to assess the impact of mitigation policies on daily life, especially the time to establish and recover from lockdowns. As such, hiFSAN may provide important constraints for health and behavioral science studies.

\section{REFERENCES AND NOTES}

1. J. N. Brune, J. Oliver, The seismic noise of the earth's surface. Bull. Seismol. Soc. Am. 49, 349-353 (1959).

2. R. K. Cessaro, Sources of primary and secondary microseisms. Bull. Seismol. Soc. Am. 84, 142-148 (1994)

3. N. M. Shapiro, M. Campillo, Emergence of broadband Rayleigh waves from correlations of the ambient seismic noise. Geophys. Res. Lett. 31, L07614 (2004). doi:10.1029/2004GL019491

4. D. E. McNamara, R. P. Buland, Ambient Noise Levels in the Continental United States. Bull. Seismol. Soc. Am. 94, 1517-1527 (2004). doi:10.1785/012003001

5. J. C. Groos, J. R. Ritter, Time domain classification and quantification of seismic noise in an urban environment. Geophys. J. Int. 179, 1213-1231 (2009). doi:10.1111/j.1365-246X.2009.04343.x

6. C. M. Boese, L. Wotherspoon, M. Alvarez, P. Malin, Analysis of Anthropogenic and Natural Noise from Multilevel Borehole Seismometers in an Urban Environment, Auckland, New Zealand. Bull. Seismol. Soc. Am. 105, 285-299 (2015). doi:10.1785/0120130288

7. D. N. Green, I. D. Bastow, B. Dashwood, S. E. Nippress, Characterizing Broadband Seismic Noise in Central London. Seismol. Res. Lett. 88, 113-124 (2017). doi:10.1785/0220160128

8. C. L. Ashenden, J. M. Lindsay, S. Sherburn, I. E. M. Smith, C. A. Miller, P. E. Malin, Some challenges of monitoring a potentially active volcanic field in a large urban area: Auckland volcanic field, New Zealand. Nat. Hazards 59, 507-528 (2011). doi:10.1007/s11069-011-9773-0

9. N. Riahi, P. Gerstoft, The seismic traffic footprint: Tracking trains, aircraft, and cars seismically. Geophys. Res. Lett. 42, 2674-2681 (2015). doi:10.1002/2015GL063558

10. N. J. Lindsey et al., arXiv:2005.04861 (2020).

11. J. Díaz, M. Ruiz, P. S. Sánchez-Pastor, P. Romero, Urban seismology: On the origin of earth vibrations within a city. Sci. Rep. 7, 15296 (2017). doi:10.1038/s41598017-15499-y Medline

12. P. Denton, S. Fishwick, V. Lane, D. Daly, Football Quakes as a Tool for Student Engagement. Seismol. Res. Lett. 89, 1902-1907 (2018). doi:10.1785/0220180078

13. D. Wilson et al., Broadband Seismic Background Noise at Temporary Seismic Stations Observed on a Regional Scale in the Southwestern United States. Bull. Seismol. Soc. Am. 92, 3335-3342 (2002). doi:10.1785/0120010234

14. C. Sohrabi et al., World Health Organization declares global emergency: A review of the 2019 novel coronavirus (COVID-19). Int. J. Surg. 76, 71-76 (2020). doi:10.1016/jijisu.2020.02.034

15. R. M. Anderson, H. Heesterbeek, D. Klinkenberg, T. D. Hollingsworth, How will country-based mitigation measures influence the course of the COVID-19 epidemic? Lancet 395, 931-934 (2020). doi:10.1016/S0140-6736(20)30567-5 Medline

16. M. Nicola et al., Evidence based management guideline for the COVID-19 pandemic. Int. J. Surg. 77, 206-216 (2020). doi:10.1016/j.jisu.2020.04.001

17. T. Laing, The economic impact of the Coronavirus 2019 (Covid-2019): Implications for the mining industry. Extr. Ind. Soc. 7, 580-582 (2020). doi:10.1016/j.exis.2020.04.003

18. A. Hoque, F. A. Shikha, M. W. Hasanat, I. Arif, A. B. A. Hamid, The Effect of Coronavirus (COVID-19) in the Tourism Industry in China. Asian J. Multidiscip. Stud. 3, 52-58 (2020)

19. M. U. G. Kraemer, C.-H. Yang, B. Gutierrez, C.-H. Wu, B. Klein, D. M. Pigott, L. du Plessis, N. R. Faria, R. Li, W. P. Hanage, J. S. Brownstein, M. Layan, A. Vespignani, H. Tian, C. Dye, O. G. Pybus, S. V. Scarpino; Open COVID-19 Data Working Group, 
The effect of human mobility and control measures on the COVID-19 epidemic in China. Science 368, 493-497 (2020). doi:10.1126/science. abb4218 Medline

20. H. Tian, Y. Liu, Y. Li, C.-H. Wu, B. Chen, M. U. G. Kraemer, B. Li, J. Cai, B. Xu, Q. Yang, B. Wang, P. Yang, Y. Cui, Y. Song, P. Zheng, Q. Wang, O. N. Bjornstad, R. Yang, B. T. Grenfell, O. G. Pybus, C. Dye, An investigation of transmission control measures during the first 50 days of the COVID-19 epidemic in China. Science 368, 638-642 (2020). doi:10.1126/science.abb6105 Medline

21. J. Zhang, M. Litvinova, Y. Liang, Y. Wang, W. Wang, S. Zhao, Q. Wu, S. Merler, C. Viboud, A. Vespignani, M. Ajelli, H. Yu, Changes in contact patterns shape the dynamics of the COVID-19 outbreak in China. Science 368, 1481-1486 (2020). doi:10.1126/science. abb8001 Medline

22. M. Chinazzi, J. T. Davis, M. Ajelli, C. Gioannini, M. Litvinova, S. Merler, A. Pastore Y Piontti, K. Mu, L. Rossi, K. Sun, C. Viboud, X. Xiong, H. Yu, M. E. Halloran, I. M. Longini Jr., A. Vespignani, The effect of travel restrictions on the spread of the 2019 novel coronavirus (COVID-19) outbreak. Science 368, 395-400 (2020). Medline

23. M. Bauwens, S. Compernolle, T. Stavrakou, J.-F. Müller, J. Gent, H. Eskes, P. F. Levelt, R. A, J. P. Veefkind, J. Vlietinck, H. Yu, C. Zehner, Impact of Coronavirus Outbreak on $\mathrm{NO}_{2}$ Pollution Assessed Using TROPOMI and OMI Observations. Geophys. Res. Lett. 47, 11 (2020). doi:10.1029/2020GL087978

24. Materials and Methods, and Network Citations are available as supplementary materials.

25. R. E. Anthony, A. T. Ringler, D. C. Wilson, E. Wolin, Do Low-Cost Seismographs Perform Well Enough for Your Network? An Overview of Laboratory Tests and Field Observations of the OSOP Raspberry Shake 4D. Seismol. Res. Lett. 90, 219228 (2019). doi:10.1785/0220180251

26. H. Lau et al., The positive impact of lockdown in Wuhan on containing the COVID19 outbreak in China. J. Travel Med. 27, taaa037 (2020). doi:10.1093/jtm/taaa037

27. S. Sherburn, B. J. Scott, J. Olsen, C. Miller, Monitoring seismic precursors to an eruption from the Auckland Volcanic Field, New Zealand. N. Z. J. Geol. Geophys. 50,1-11 (2007). doi:10.1080/00288300709509814

28. Center for International Earth Science Information Network CIESIN Columbia University, Gridded population of the world, version 4 (GPWv4): Population density. Revision 11, Accessed 2 June 2020 (2018); https://doi.org/10.7927/H49C6VHW.

29. W. Zürn, J. Exß, H. Steffen, C. Kroner, T. Jahr, M. Westerhaus, On reduction of longperiod horizontal seismic noise using local barometric pressure. Geophys. J. Int. 171, 780-796 (2007). doi:10.1111/j.1365-246X.2007.03553.x

30. B. Gutenberg, C. F. Richter, Frequency of earthquakes in California. Bull. Seismol. Soc. Am. 34, 185-188 (1944)

31. Z. E. Ross, D. T. Trugman, E. Hauksson, P. M. Shearer, Searching for hidden earthquakes in Southern California. Science 364, 767-771 (2019). doi:10.1126/science.aaw6888 Medline

32. E. S. Cochran, To catch a quake. Nat. Commun. 9, 2508 (2018). doi:10.1038/s41467-018-04790-9 Medline

33. G. J. H. McCall, Geohazards and the urban environment. Geol. Soc. London Eng. Geol. Spec. Publ. 15, 309-318 (1998). doi:10.1144/GSL.ENG.1998.015.01.31

34. M. Lehujeur, J. Vergne, J. Schmittbuhl, A. Maggi, Characterization of ambient seismic noise near a deep geothermal reservoir and implications for interferometric methods: A case study in northern Alsace, France. Geotherm. Energy 3, 3 (2015). doi:10.1186/s40517-014-0020-2

35. G. Hillers, M. Campillo, Y.-Y. Lin, K.-F. Ma, P. Roux, Anatomy of the high-frequency ambient seismic wave field at the TCDP borehole. J. Geophys. Res. 117, B06301 (2012). doi:10.1029/2011JB008999

36. M. Picozzi, S. Parolai, D. Bindi, A. Strollo, Characterization of shallow geology by high-frequency seismic noise tomography. Geophys. J. Int. 176, 164-174 (2009). doi:10.1111/i.1365-246X.2008.03966.x

37. F. Brenguier, P. Boué, Y. Ben-Zion, F. Vernon, C. W. Johnson, A. Mordret, 0. Coutant, P.-E. Share, E. Beaucé, D. Hollis, T. Lecocq, Train Traffic as a Powerful Noise Source for Monitoring Active Faults With Seismic Interferometry. Geophys. Res. Lett. 46, 9529-9536 (2019). doi:10.1029/2019GL083438 Medline

38. T. Lecocq et al., ThomasLecocq/2020_Science_GlobalQuieting: First Release v1.0, Zenodo (2020) https://doi.org/10.5281/zenodo.3944739

39. A. Aktay et al., arXiv:2004.04145 (2020).
40. M. Schäfer, M. Strohmeier, V. Lenders, I. Martinovic, M. Wilhelm, IPSN-14 Proceedings of the 13th International Symposium on Information Processing in Sensor Networks (IEEE, 2014), pp. 83-94.

41. S. R. Proud, Go-Around Detection Using Crowd-Sourced ADS-B Position Data. Aerospace 7, 16 (2020). doi:10.3390/aerospace7020016

42. D. E. McNamara, R. I. Boaz, U.S. Geol. Surv. Open-File Rept 2010-1292, 41 (2010).

43. R. E. Anthony, A. T. Ringler, D. C. Wilson, M. Bahavar, K. D. Koper, How Processing Methodologies Can Distort and Bias Power Spectral Density Estimates of Seismic Background Noise. Seismol. Res. Lett. 91, 1694-1706 (2020). doi:10.1785/0220190212

44. M. Beyreuther, R. Barsch, L. Krischer, T. Megies, Y. Behr, J. Wassermann, ObsPy: A Python Toolbox for Seismology. Seismol. Res. Lett. 81, 530-533 (2010). doi:10.1785/gssrl.81.3.530

45. T. Megies, M. Beyreuther, R. Barsch, L. Krischer, J. Wassermann, ObsPy - What can it do for data centers and observatories? Ann. Geophys. 54, 47-58 (2011). doi:10.4401/ag-4838

46. L. Krischer, T. Megies, R. Barsch, M. Beyreuther, T. Lecocq, C. Caudron, J. Wassermann, ObsPy: A bridge for seismology into the scientific Python ecosystem. Comput. Sci. Discov. 8, 014003 (2015). doi:10.1088/17494699/8/1/014003

47. R. B. Blackman, J. W. Tukey, The measurement of power spectra from the point of view of communications engineering-Part I. Bell Syst. Tech. J. 37, 185-282 (1958). doi:10.1002/i.1538-7305.1958.tb03874.x

48. P. Welch, The use of fast Fourier transform for the estimation of power spectra: A method based on time averaging over short, modified periodograms. IEEE Trans. Audio Electroacoust. 15, 70-73 (1967). doi:10.1109/TAU.1967.1161901

49. J. D. Hunter, Matplotlib: A 2D Graphics Environment. Comput. Sci. Eng. 9, 90-95 (2007). doi:10.1109/MCSE.2007.55

50. R. Lacassin, M. Devès, S. P. Hicks, J.-P. Ampuero, R. Bossu, L. Bruhat, D. F. Wibisono, L. Fallou, E. J. Fielding, A.-A. Gabriel, J. Gurney, J. Krippner, A. Lomax, M. M. Sudibyo, A. Pamumpuni, J. R. Patton, H. Robinson, M. Tingay, S. Valkaniotis, Rapid collaborative knowledge building via Twitter after significant geohazard events. Geosci. Commun. 3, 129-146 (2020). doi:10.5194/gc-3-129-2020

51. T. Kluyver et al., Positioning and Power in Academic Publishing: Players, Agents and Agendas, F. Loizides, B. Schmidt, eds. (IOS Press, 2016), pp. 87-90.

52. T. Lecocq, F. Massin, C. Satriano, M. Vanstone, T. Megies, SeismoRMS - A simple Python/Jupyter Notebook package for studying seismic noise changes (2020).

53. L. Krischer, Y. A. Aiman, T. Bartholomaus, S. Donner, M. Driel, K. Duru, K. Garina, K. Gessele, T. Gunawan, S. Hable, C. Hadziioannou, M. Koymans, J. Leeman, F. Lindner, A. Ling, T. Megies, C. Nunn, A. Rijal, J. Salvermoser, S. T. Soza, C. Tape, T. Taufiqurrahman, D. Vargas, J. Wassermann, F. Wölfl, M. Williams, S. Wollherr, H. Igel, seismo-live: An Educational Online Library of Jupyter Notebooks for Seismology. Seismol. Res. Lett. 89, 2413-2419 (2018). doi:10.1785/0220180167

54. QGIS Development Team, QGIS Geographic Information System, Open Source Geospatial Foundation (2020).

\section{ACKNOWLEDGMENTS}

We sincerely thank the editor, two anonymous reviewers, Tarje Nissen-Meyer, and Janet Slate for their comments, which have improved the manuscript. We are extremely grateful to all seismic network managers, operators, and technicians who have helped to facilitate the raw global seismic dataset (24). We also kindly acknowledge all the passionate community seismologists for running their "home" seismometers and participating, indirectly, to a better understanding of the Earth. Any use of trade, firm, or product names is for descriptive purposes only and does not imply endorsement by the U.S. Government. We dedicate this community-led study to all essential workers who have kept our countries going during these difficult times. Funding: P.K. was funded by a Royal Society University Research Fellowship (URF\R1\180377). P.B. and M.J. acknowledge support from the International Training Course "Seismology and Seismic Hazard Assessment" funded by the GeoForschungsZentrum Potsdam (GFZ) and the German Federal Foreign Office through the German Humanitarian Assistance program (grant S08-60 321.50 ALL 03/19). P.B also acknowledges financial support from the Boğaziçi University Research Fund (BAP 15683). O.F.C.d.O acknowledges funding from a Young Investigator Grant from the Human Frontier Science Program (HFSP - project number RGY0072/2017). C.P.E. and E.S. 
acknowledge funding from the HELPOS Project "Hellenic Plate Observing System" (MIS 5002697). L.E. and S.S.-K. acknowledge funding from a VIDI project from the Dutch Research Council (NWO project number 864.14.005).

G.A.F. acknowledges contributions from the Observatorio San Calixto, which is supported by the Air Force Technical Application Center (AFTAC). C.R.L. acknowledge funding from the NSF Graduate Research Fellowship Program (grant No. DGE-1745301). V.-H.M. and R.D.P. acknowledge support from grant CONACYT-299766. R.D.P. acknowledges support from the UNAM-DGAPA postdoctoral scholarship. J.0. acknowledges support from the Agencia Nacional de Investigación y Desarrollo (Scholarship ANID-PFCHA / Doctorado Nacional / 2020-21200903). S.P. acknowledges financial support from the Natural Environment Research Council (NE/R013144/1). A.E.R. acknowledges support from the K.H. Renlund foundation. M.K.S. acknowledges the New Zealand Earthquake Commission (EQC Project No 20796). H.X. acknowledges support from a Multidisciplinary Research on the Coronavirus and its Impacts ( $\mathrm{MRCl}$ ) grant from UC Santa Barbara. The Australian Seismometers in Schools data used in this research are supported by AuScope, enabled by the Australian Commonwealth NCRIS program. A.O. acknowledges support from the project RESIST, funded by the Belgian Federal Science Policy (contract SR/00/305) and the Luxembourg National Research Fund. Author contributions: TL designed and led the research; TL, SH, KVN, KvW, PK and RDP processed and visualized the data and drafted the manuscript; FM contributed to the software development and provided the Supplementary video; GH thoroughly edited and reviewed the manuscript. All 76 authors processed seismic data, took part in discussions, and performed a full interactive review of the original and revised manuscripts. Competing interests: The authors declare no competing interests. Data and materials availability: The raw data used to compute the hiFSAN were obtained from different networks and data providers (24). The computed data and codes used to analyze and plot Figs. 1 to 4 are available from the companion repository (38):

https://github.com/ThomasLecocq/2020 Science GlobalQuieting (last accessed July 2020)

\section{SUPPLEMENTARY MATERIALS}

science.sciencemag.org/cgi/content/full/science.abd2438/DC1

Materials and Methods

Supplementary Text

Figs. S1 to S9

Tables S1 to S3

References (39-54)

Movie S1

10 June 2020; accepted 14 July 2020

Published online 23 July 2020

10.1126/science.abd2438 


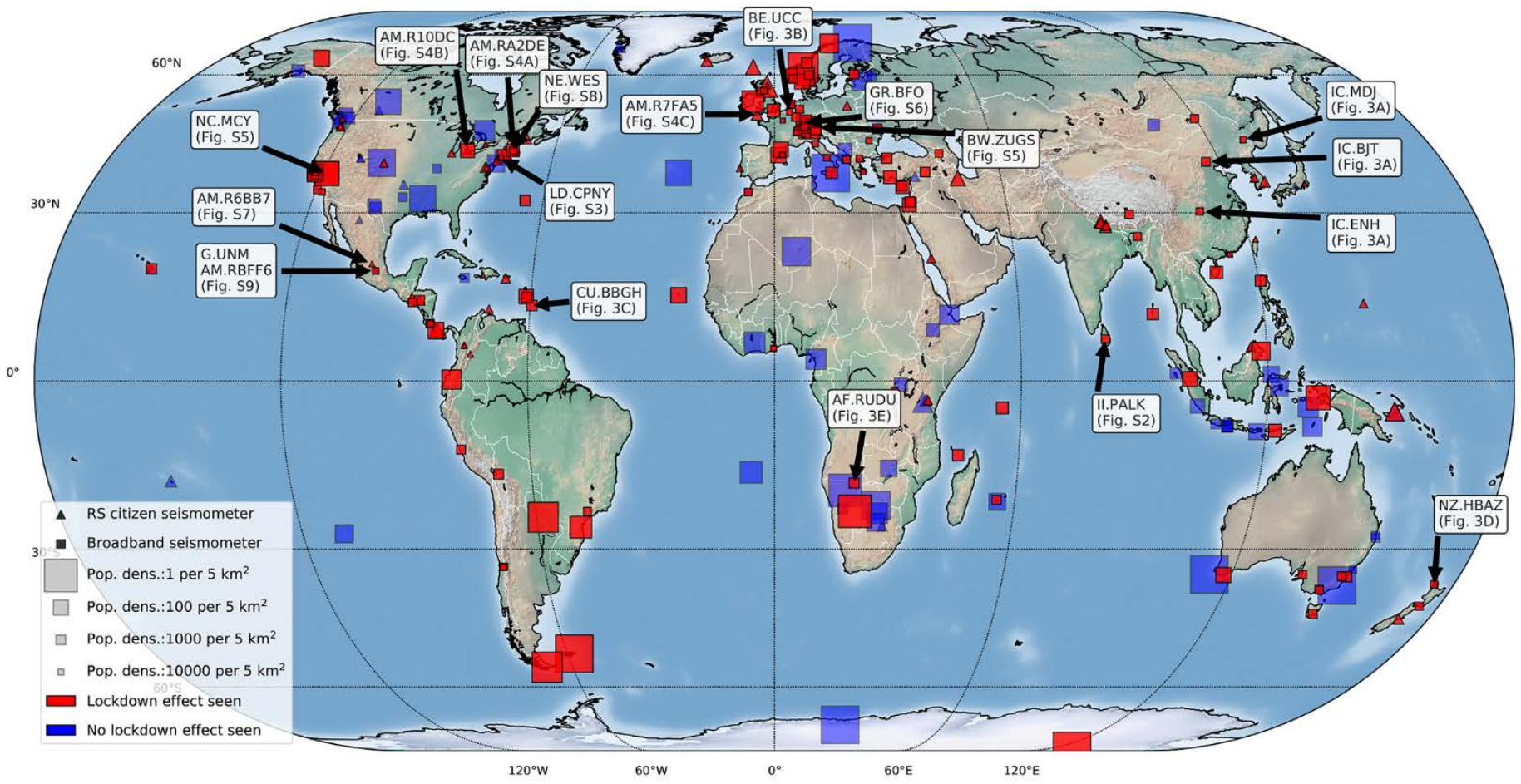

Fig. 1. Worldwide seismic station locations. Locations of the 268 global seismic stations with usable data (e.g., no long data gaps, working sensors) we analyzed. Lockdown effects are observed (red) at 185 out of 268 stations. Symbol size is scaled by the inverse of population density (28) to emphasize stations located in remote areas. The stations we labeled are discussed in detail in the text. 


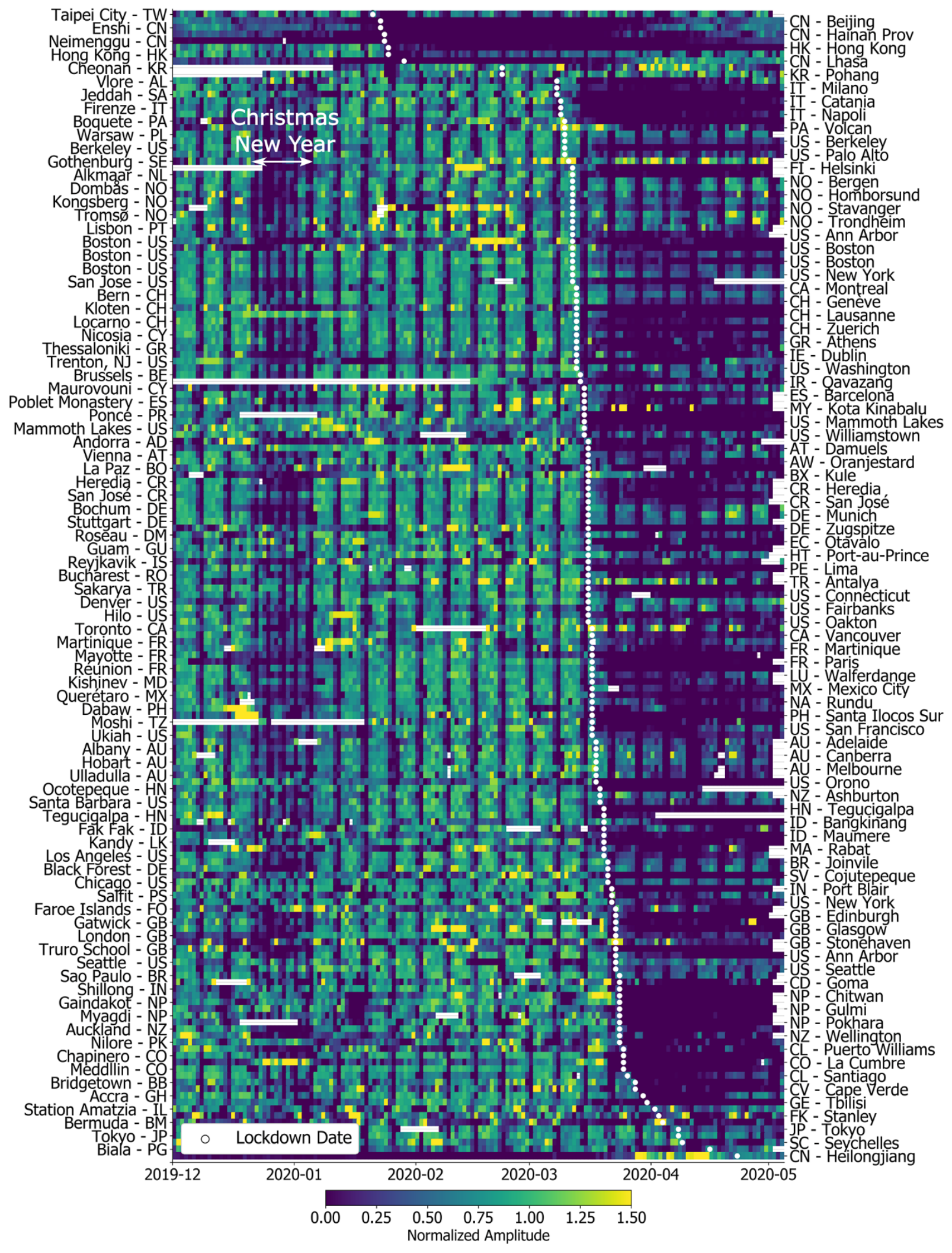

Fig. 2. Global temporal changes in seismic noise. Global daily median hiFSAN based on displacement data (24), normalized to percentage variation of the baseline before lockdown measures, and sorted by lockdown date. Data gaps are colored white. Location and country code of the station are indicated, while fig. S1 also includes the network and station code. 

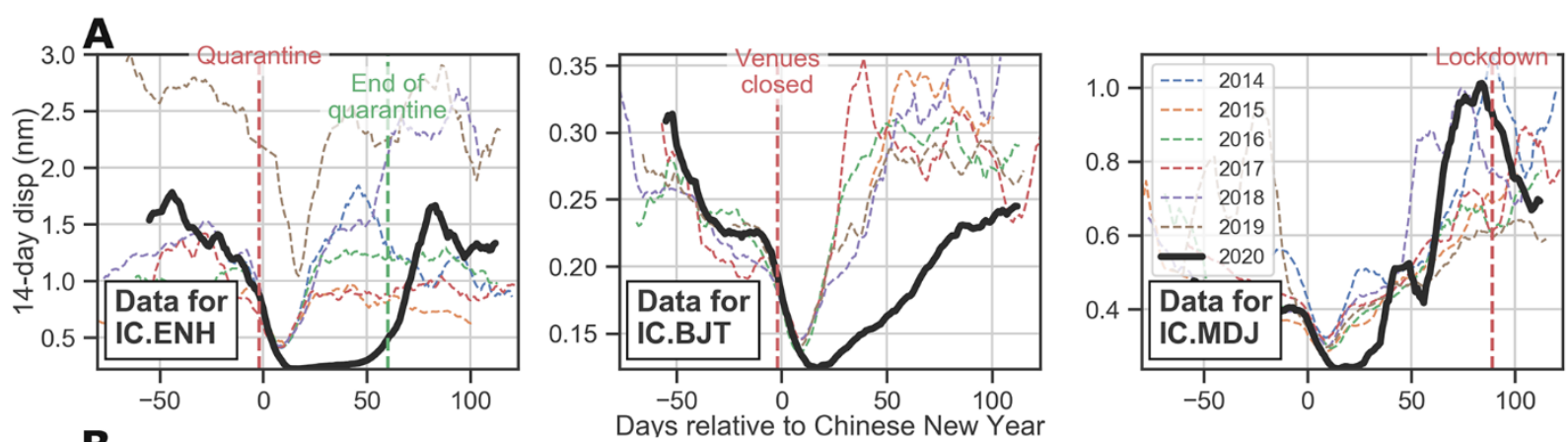

B
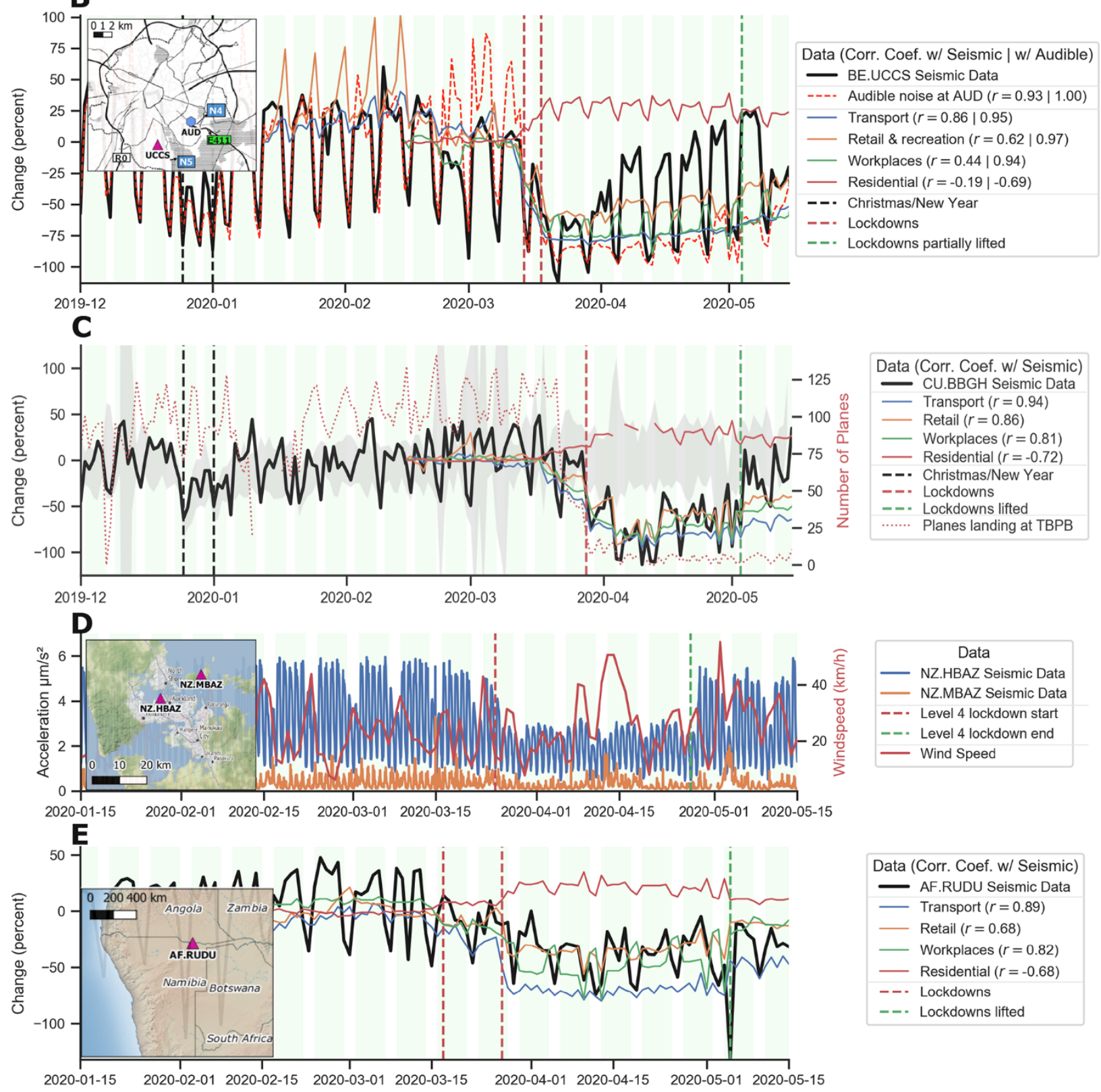

Data (Corr. Coef. w/ Seismic)
- AF.RUDU Seismic Data
- Transport $(r=0.89)$
- Retail $(r=0.68)$
- Workplaces $(r=0.82)$
- Residential $(r=-0.68)$
--- Lockdowns
--- Lockdowns lifted

Fig. 3. Regional examples of the 2020 seismic noise quiet period. Examples showing different features of the lockdown seismic signal changes in regional settings. We filtered the hiFSAN data between 4 and $14 \mathrm{~Hz}$ and present temporal changes either as displacement (A), acceleration (D) or as percentage change compared to the baseline before lockdown ( $B, C$ and $E$ ) with the panels in $(A)$ also comparing to the baseline of corresponding time periods in prior years. Individual seismic stations are identified by network. station codes (IC.ENH, BE.UCCS, etc.). The legends of (B-E) include correlation coefficients $r$ with mobility data (24). (A) Lockdown effects at three stations in China compared to the Chinese New Year holiday in previous years. (B) Lockdown effects in hiFSAN compared with audible environmental noise and independent mobility data in Brussels, Belgium. (C) Lockdown effect in Barbados compared to noise levels in the last decade (in gray) and correlation with local flight data at the Grantley Adams International Airport (TBPB) (24). (D) Lockdown noise reduction recorded on borehole seismometers in Auckland, New Zealand. (E) Lockdown noise reduction in a region of low population density in Rundu, Namibia.

First release: 23 July 2020 

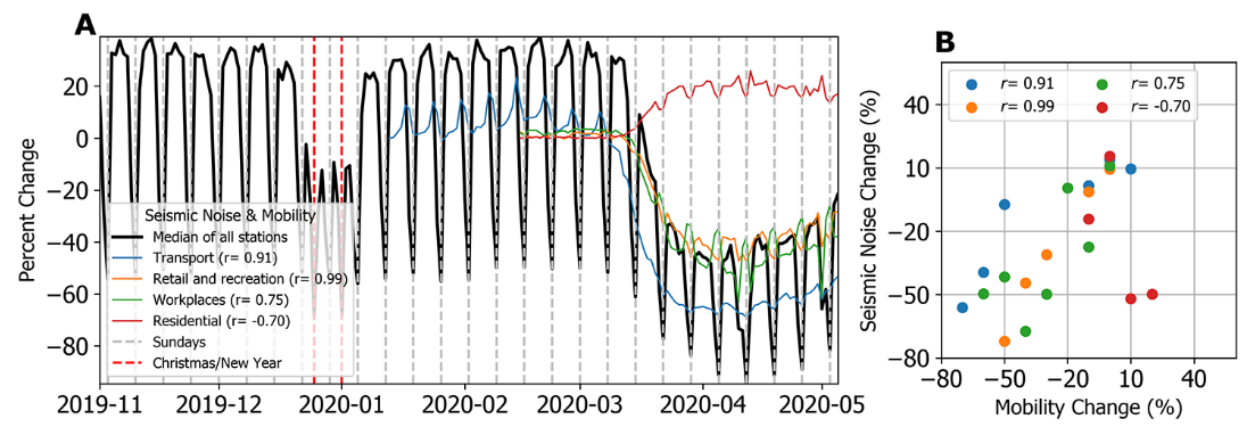

Fig. 4. Global changes in seismic noise compared to population mobility trends. (A) Comparison between temporal changes in global daily median hiFSAN based on the 185 stations that observed lockdown effects and population mobility changes (24). (B) Scatter-plot to illustrate the correlation between the binned ( $10 \%$ bins) time series of seismic noise changes and all categories of mobility data in (A). Percentage changes are given relative to a pre-lockdown baseline. All categories show a strong positive correlation, apart from time spent in residential premises, which is anti-correlated. 